\title{
Bezug von Säule 3a-Geldern planen
}

Viele Erwerbstätige nutzen die Vorteile der Säule 3a und ziehen jedes Jahr die geleisteten Prämien in der Steuererklärung ab. Steuern können aber nicht nur während der Laufzeit, sondern auch bei der Auszahlung gespart werden. Mit der Pensionierung werden die Säule 3a-Gelder vom sogenannten gebundenen Vermögen ins freie Vermögen transferiert, was eine einmalige Kapitalleistungssteuer zur Folge hat. Wie die meisten Steuersätze beinhaltet auch dieser eine Progression. Das bedeutet, dass höhere Guthaben prozentual auch höher besteuert werden. Dabei werden alle Vorsorgeleistungen, d. h. Auszahlungen aus der Säule 3a und Kapitalleistungen aus der beruflichen Vorsorge, innerhalb eines Jahres addiert und gemeinsam besteuert.

Deshalb beginnt eine gute Planung bereits viele Jahre vor der Pensionierung. Spätestens aber fünf Jahre vor Erreichen des ordentlichen Pensionsalters sollten die Auszahlungen so geplant sein, dass die Guthaben in verschiedenen Jahren zur Auszahlung gelangen. Im folgenden Beispiel zeigen wir Ihnen auf, welche Einsparungen dadurch möglich sind:

\begin{tabular}{|c|c|c|c|c|c|c|c|c|c|c|c|}
\hline Kanton* & $1 \times 400000$ & $2 \times 200000$ & Einsparung & Kanton * & $1 \times 400000$ & $2 \times 200000$ & Einsparung & Kanton * & $1 \times 400000$ & $2 \times 200000$ & Einsparung \\
\hline AG & 38892 & 30936 & $20,46 \%$ & GR & 20002 & 17334 & $13,34 \%$ & SZ & 22882 & 12986 & $43,25 \%$ \\
\hline Al & 23092 & 19080 & $17,37 \%$ & JU & 32287 & 28014 & $13,23 \%$ & TG & 30292 & 27624 & $8,81 \%$ \\
\hline AR & 31132 & 28464 & $8,57 \%$ & LU & 31652 & 25836 & $18,37 \%$ & $\mathrm{TI}$ & 23492 & 20824 & $11,36 \%$ \\
\hline $\mathrm{BE}$ & 30031 & 23304 & $22,40 \%$ & NE & 37167 & 34500 & $7,18 \%$ & UR & 25256 & 22588 & $10,56 \%$ \\
\hline BL & 21452 & 18784 & $12,44 \%$ & NW & 31228 & 26742 & $14,37 \%$ & VD & 43239 & 33916 & $21,56 \%$ \\
\hline BS & 36483 & 30566 & $16,22 \%$ & OW & 29476 & 26808 & $9,05 \%$ & VS & 32192 & 22424 & $30,34 \%$ \\
\hline FR & 43785 & 32338 & $26,14 \%$ & SG & 31052 & 24144 & $22,25 \%$ & ZG & 24726 & 17726 & $28,31 \%$ \\
\hline GE & 29108 & 22924 & $21,25 \%$ & SH & 25473 & 19656 & $22,84 \%$ & $\mathrm{ZH}$ & 30197 & 23384 & $22,56 \%$ \\
\hline GL & 27572 & 24904 & $9,68 \%$ & so & 31698 & 25510 & $19,52 \%$ & & & & \\
\hline
\end{tabular}

* Für die Gemeindesteuern wurden die Kantonshauptorte verwendet.

\section{Säule 3a-Lösungen für Ärzte}

Wir arbeiten mit den meisten Versicherungsgesellschaften und verschiedenen Banken zusammen, um Ihnen die besten Lösungen anbieten zu können. Zudem verfügen wir über Spezialprodukte, womit Sie exklusiv über FMH Insurance Services zu weiteren Vorteilen kommen. Gerne stehen Ihnen unsere Berater für weitere Informationen zur Verfügung oder unterbreiten Ihnen eine persönliche Offerte.

\section{Antworttalon}

Vorname/Name

Adresse

PLZ/Ort

Geburtsdatum

Telefon Privat/Geschäft

Beste Zeit für einen Anruf

E-Mail-Adresse

Ich möchte den Bezug meiner Vorsorgegelder steuerlich optimieren. Bitte rufen Sie mich an.

Ich möchte die Säule 3a-Lösungen für Ärzte kennenlernen. Bitte rufen Sie mich an.

Ich möchte mehr über die anderen Dienstleistungen von FMH Insurance Services erfahren.

Bitte rufen Sie mich an.

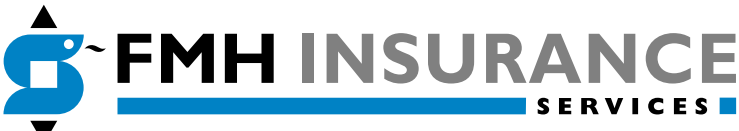

Roth Gygax \& Partner AG — Koordinationsstelle Moosstrasse 2 a 3073 Gümligen

Telefon 0319595000 a Fax 0319595010 mail@fmhinsurance.ch = www.fmhinsurance.ch 